\title{
Increased Susceptibility of Arterial Tissue to Wire Perforation with the Application of High Frequency Mechanical Vibrations
}

\author{
Mark Wylie \\ Technological University Dublin, mark.wylie@tudublin.ie \\ Garrett McGuinness \\ Dublin City University \\ Graham Gavin \\ Technological University Dublin, graham.gavin@tudublin.ie
}

Follow this and additional works at: https://arrow.tudublin.ie/biodevart

Part of the Biomedical Engineering and Bioengineering Commons

\section{Recommended Citation}

Wylie, M., McGuinness, G., \& Gavin, G. (2012) Increased Susceptibility of Arterial Tissue to Wire Perforation with the Application of High Frequency Mechanical Vibrations. Biomedical Engineering, IEEE Transactions on, vol.PP, no.99, pp.1. doi:10.1109/TBME.2012.2184286

This Article is brought to you for free and open access by the Biomedical Devices and Assistive Technology Research Group at ARROW@TU Dublin. It has been accepted for inclusion in Articles by an authorized administrator of ARROW@TU Dublin. For more information, please contact arrow.admin@tudublin.ie, aisling.coyne@tudublin.ie,gerard.connolly@tudublin.ie. Funder: Strand 1

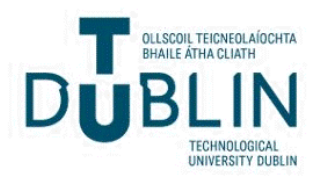




\title{
Increased Susceptibility of Arterial Tissue to Wire Perforation with the Application of High Frequency Mechanical Vibrations
}

\author{
Mark P. Wylie, Garrett B. McGuinness and Graham P. Gavin
}

\begin{abstract}
High frequency mechanical vibrations $(20-50 \mathrm{kHz})$, delivered via small diameter flexible wire waveguides represent a minimally invasive technology for the treatment of chronic total occlusions (CTOs) and in other tissue ablation applications. Tissue disruption is reported to be caused by repetitive mechanical contact and cavitation. This work focuses on the effects of vibrating wire waveguides in contact with arterial tissue. An apparatus with clinically relevant parameters was used, characterized as operating at $22.5 \mathrm{kHz}$ and delivering amplitudes of vibration of 17.8 - $34.3 \mu \mathrm{m}$ (acoustic intensity, $I_{\text {SATA }}: 1.03-3.83 \mathrm{~W} / \mathrm{cm}^{2}$ ) via $1.0 \mathrm{~mm}$ diameter waveguides. Inertial cavitation (in water at $37^{\circ} \mathrm{C}$ ) was determined to occur above amplitudes of vibration greater than $31.4 \mu \mathrm{m}\left(\mathrm{I}_{\mathrm{SATA}}=\mathbf{3 . 2 1}\right.$ $W / \mathrm{cm}^{2}$ ). The energized waveguides were advanced through tissue samples (porcine aorta) and the force profiles were measured for a range of acoustic intensities. The results show that the tissue perforation initiation force, perforation initiation energy and total energy required to perforate the tissue reduces with increasing acoustic intensity. No significant reduction in perforation force or energy was observed in the inertial cavitation region. Multistage perforation was evident through the force profile and histological examination of the tissue samples post wire waveguide perforation.
\end{abstract}

Index Terms - Angioplasty, Soft Tissue Ablation, Ultrasound, Waveguides

\section{INTRODUCTION}

$\mathrm{T}$ herapeutic ultrasound for tissue and thrombus ablation and disruption encompasses a number of techniques. They can be broadly classified according to frequency of operation, acoustic intensity range and delivery method. Methods include catheter-delivered external transducer systems (wire waveguide) and transcutaneous-delivered external ultrasound

Manuscript received June 17, 2011, accepted December 5, 2011. This work was supported in part by a Strand I scholarship from the Higher Education Authority, Ireland. M.P. Wylie is with the School of Manufacturing and Design Engineering, Dublin Institute of Technology, Dublin, Ireland and the Biomedical Devices and Assistive Technologies Research Group, DIT (email: mark.wylie@dit.ie). G.B. McGuinness is with the School of Mechanical and Manufacturing Engineering, Dublin City University, Dublin, Ireland (email: garrett.mcguinness@dcu.ie). G.P. Gavin is with the School of Manufacturing and Design Engineering, Dublin Institute of Technology, Dublin, Ireland and leads the Biomedical Devices and Assistive Technologies Research Group, DIT (phone: 353-1-4023952; fax: 353-1-4023986; e-mail: graham.gavin@dit.ie).

Copyright (c) 2010 IEEE. Personal use of this material is permitted. However, permission to use this material for any other purposes must be obtained from the IEEE by sending an email to pubs-permissions@ieee.org. such as High Intensity Focused Ultrasound (HIFU) [1, 2]. HIFU treatments for soft tissue ablation (i.e. histotripsy) fractionate and disrupt target tissue through cavitation and generally operate at acoustic intensities many orders of magnitude greater than those used in wire waveguide delivery; and therefore tissue disruption and ablation mechanisms may differ $[1,3]$.

Therapeutic ultrasound wire waveguide devices deliver high frequency $(20-50 \mathrm{kHz})$ mechanical vibrations to the waveguide distal tip of approximately $0-50 \mu \mathrm{m}$ in amplitude [4-8]. Small diameter wire waveguides may be supported by a catheter and often terminate with an enlarged distal tip. The details around general device design are explained in greater detail elsewhere [4-7, 9]. Wire waveguide delivery of ultrasound has been applied for thrombus dissolution and tissue ablation, for a range of tissue types, from soft tissue to fibrous and hard calcified tissues $[4,10]$.

More recently, in 2005 and 2007, a device using high frequency mechanical vibrations delivered via a wire waveguide has been approved for use in the recanalisation of chronic totally occluded (CTO) atherosclerotic lesions, in Europe and the United States, respectively $[11,12]$.

CTOs can be identified in approximately $16 \%$ of all patients undergoing angioplasty and the ability of a guidewire to cross the lesion appears to be critical to the outcome of standard dilation procedures; a key success indicator in $80 \%$ of all cases [13]. Calcifications and fibrous tissue formation is commonly present in CTOs. They are associated with an increased potential for arterial wall perforation during treatment with traditional devices when compared to subtotally occluded vessels. This may be a result of the distal section of the guidewire or subsequent device being deflected by the hard diseased lesion cap toward the surrounding healthy elastic artery wall or by entering a false lumen $[14,15]$.

This work investigates the potential for arterial perforation with high frequency mechanical wire waveguides but also examines the fundamentals of soft tissue disruption and ablation by wire waveguides at lower acoustic intensities. This may offer insight into the failure mechanics of soft elastic tissue perforation using high frequency wire waveguides. This may also be beneficial in applications where intentional perforation of soft elastic tissue is required.

\section{A. High frequency mechanical waveguide delivery}

The mechanical vibrations at the distal tip of the wire 
waveguide are reported to selectively remove inelastic diseased tissue and thrombus through a combination of direct contact and cavitation with minimal disruption to the surrounding healthy arterial wall. Other distal tip effects reported include sub-cavitation acoustic pressures and acoustic streaming [8].

Some investigators propose that diseased plaque ablation is only evident above the cavitation threshold [16]. A similar response was also observed by Rosenschein et al who reported that disruption of thrombus only occurred above the cavitation threshold [10]. Results from tests conducted by Drobinski et $a l$ on coronary and peripheral arteries show that up to $70 \%$ of the blockage can be removed by this method [17]. Fischell et al [18] also conducted a study using this type of energy for ablation of atherosclerotic plaque in rabbit thoracic artery and human cadaver iliofemoral arteries, reporting effective recanalisation of the artery. They also found that the high frequency energy induces smooth muscle relaxation, a secondary effect which reduces vaso-constriction during catheterization.

\section{B. Cavitation detection}

Important to the understanding and evaluation of these devices in tissue disruption is the ability to detect the onset of cavitation. In therapeutic ultrasound, the two main types of cavitation are:

1) Stable cavitation, where the radius of the cavitation bubbles oscillates around an equilibrium value over a considerable number of acoustic cycles without the generation of bubble collapse [19] and,

2) Inertial cavitation, where the bubble rapidly grows and collapses a number of times over a single acoustic cycle, and is commonly associated with damage mechanisms [20].

Cavitation can be observed to some degree by the naked eye. When using small diameter wire waveguides (and hence small localized cavitation regions) in often inaccessible locations near tissue, other methods must be employed. Cavitation can be measured passively by analyzing the acoustic frequency profile generated by the vibrating waveguide using a hydrophone. This method is outlined in the ANSI Bubble Detection and Cavitation Monitoring report [21]. Similar methods based on this have been reported by others [22-25].

\section{Soft Tissue Cutting}

Studies of the failure mechanisms of soft healthy elastic tissue when subjected to this form of energy suggest that the tissue may be failing due to a combination of mechanisms such as soft tissue fragmentation, mechanical and thermal ablation (whereby the water content of the soft tissue lowered as a result of thermal absorption rendering tissue susceptible to brittle failure) or fiber bundle de-striation [26-28].

A number of authors have presented work on perforation and cutting of soft tissues with traditional (without high frequency mechanical vibration) needles and scalpels and have established methods for quantifying the energy needed to achieve this [29, 30]. McCarthy et al. [29] investigated the cutting of soft tissues with scalpels. They describe the cut initiation energy, $\mathrm{E}_{\mathrm{i}}$, required to initiate a cut in soft tissues.
Given that tissues deforms, initially, to some penetration depth, $\delta_{\mathrm{i}}$, under loading prior to failure, $\mathrm{E}_{\mathrm{i}}$, is defined as:

$\mathrm{E}_{\mathrm{i}}=\int_{\delta \mathrm{i}} \mathrm{F} \mathrm{dx}$

Common therapeutic ultrasound systems, such as HIFU generate acoustic intensities many orders of magnitude greater than those of small diameter high frequency wire waveguide devices for localized tissue ablation. It is at these localized lower acoustic intensities that soft tissue disruption is not well documented. While clinical outcomes in the treatment of CTOs using this technique have been positive $[5,26,31]$, the effects of high frequency mechanical wire waveguides in contact with surrounding healthy arterial tissue and general soft tissues has not yet been investigated fully.

This study focuses on determining how high frequency mechanical wire waveguides perforate porcine arterial tissue when compared with non-energized wires. To do this an ultrasonic wire waveguide apparatus, with known performance characteristics, will be used to perforate porcine arterial tissue The perforation initiation force $\left(\mathrm{F}_{\mathrm{i}}\right)$, perforation initiation energy $\left(E_{i}\right)$ and total perforation energy $\left(E_{t}\right)$ required for arterial perforation, for a range of acoustic intensities, will be determined.

\section{Methodology}

\section{A. High frequency wire waveguide apparatus development and characterization}

An apparatus, capable of delivering mechanical vibrations via small diameter nickel-titanium (NiTi) wire waveguides, developed previously and explained in detail elsewhere [32] was used in this study, see Figure 1. Wires of $1.0 \mathrm{~mm}$ diameter were used in all experiments reported here. While these wire waveguides are larger than guidewires traditionally used, they aim to replicate distal tip geometry and acoustic output.

Some modifications were made to the apparatus including a new external housing and sealing system for the wire waveguide and acoustic horn. The inclusion of these modifications helps stabilize the waveguides by reducing lateral vibrations and increasing wire waveguide time to failure, important for tissue testing.

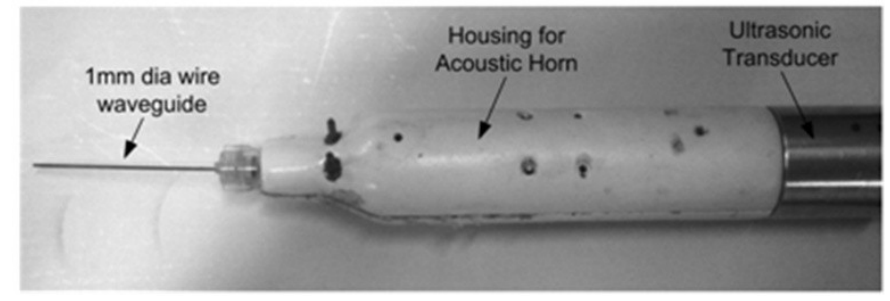

Fig. 1. Image of high frequency wire waveguide apparatus and attached 1.0 $\mathrm{mm}$ diameter wire waveguide.

The apparatus used in this experiment was adapted from an ultrasonic sonifier (Branson Ultrasonics@) whose system characteristics were very sensitive. By adding wire waveguides, connectors (essentially a mass) and additional seals the system's performance was altered. It was necessary to characterize both the operational frequency and the wire 
waveguide distal tip amplitude of vibration for a range of generator input power settings ( 0 - 5 arbitrary units).

Using these operating parameters the maximum distal tip pressure, $\mathrm{P}_{0}$, and spatial-average-temporal-average acoustic intensity at the waveguide radiating face, $\mathrm{I}_{\mathrm{SATA}}$, is given by equation 2 and 3 , respectively [3, 33].

$\mathrm{P}_{0}=(2 \pi \mathrm{f})^{2} a \rho \xi_{0}(\mathrm{~Pa})$

$\mathrm{I}_{\mathrm{SATA}}=\mathrm{P}_{0}^{2} / 2 \rho \mathrm{c}\left(\mathrm{W} / \mathrm{m}^{2}\right)$

where $\rho$ is the density of the fluid medium, $\mathrm{c}$ is the speed of sound in fluid medium, $\xi_{0}$ is the amplitude of vibration of the radiating face, $\mathrm{f}$ is the frequency of vibration and $a$ is the radius of the acoustic source.

Nyborg describes the onset of cavitation in water, in the frequency range of $20-50 \mathrm{kHz}$ with suitable gas nuclei present, above pressure amplitudes in the range of $0.1-0.2 \mathrm{MPa}$, corresponding to acoustic intensities of approximately 2-3 $\mathrm{W} / \mathrm{cm}^{2}[34]$.

\section{B. Experimental test rig and sensing equipment}

An automated experimental test rig was designed and developed to accommodate the apparatus and wire waveguide assembly, see Figure 2. These were attached to a linear lead screw system which was driven by a high torque stepper motor and could advance the wire waveguide apparatus over a range of feed rates. For this work a constant feed rate of $38 \pm 2$ $\mathrm{mm} / \mathrm{min}$ was used for all tests.

This motor was controlled using a stepper motor driver board via a data acquisition system. The rig also incorporated a stainless steel thermostatic tank (Clifton 1000 Watt, model NE1B-14), with internal dimensions of $325 \times 300 \times 150 \mathrm{~mm}$. This tank was filled with tap water and the temperature was held at $37^{\circ} \mathrm{C} \pm 0.1$. This tank would allow for the submersion of tissue samples and a strain-based force measurement sensor during tissue testing.

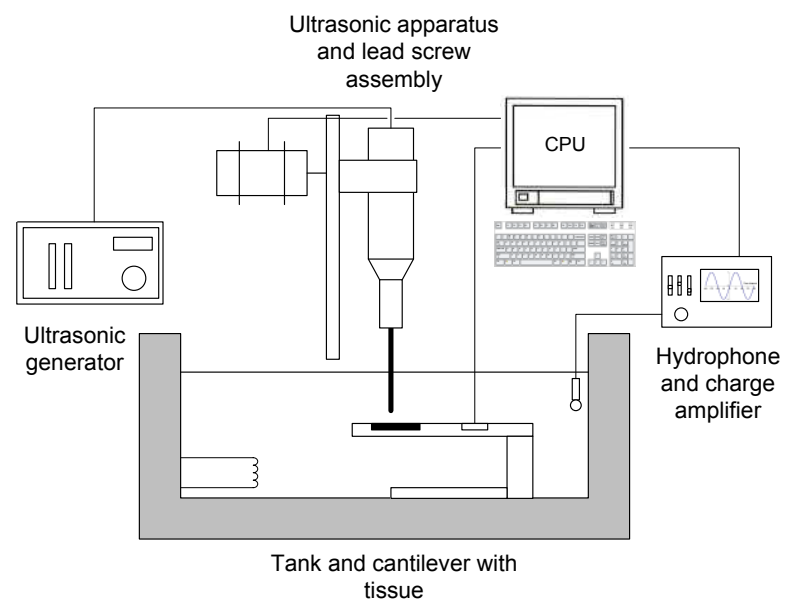

Fig. 2. Schematic diagram of wire waveguide apparatus and experimental rig.

\section{Force and displacement measurement}

The wire waveguide distal tip-tissue interaction force was measured by securing tissue samples in a cantilever beam arrangement, see Figure 3a. A guide slot (1.5 mm deep) in the beam was used to align the strips of tissue. This also had a 3.0 $\mathrm{mm}$ diameter hole to allow for the wire waveguide to fully perforate the tissue. An upper plate was used to clamp the tissue securely in the beam. The cantilever beam assembly included a half-bridge temperature compensation strain gauge arrangement (KFG N10C2, Kyowa Electronic Instruments Co. Ltd, Japan) calibrated to provide force feedback. This arrangement was sealed using epoxy resin (Araldite, Huntsman Advanced Materials, USA). A low pass filter (100 $\mathrm{Hz}$ ) was applied to the measured force signal to omit superimposed higher frequency noise components.

To determine wire waveguide indentation into the tissue, $\delta_{\mathrm{i}}$, two parameters were required, $\delta_{\text {tip }}$ and $\delta_{\text {beam }}$, see Figure $3 \mathrm{a}$. The waveguide travel, $\delta_{\text {tip }}$, is measured via the stepper motor step pulse count $\left(1.8^{0}\right.$ step $\left.\pm 0.5 \%\right)$. The beam deflection, $\delta_{\text {beam, }}$, was determined experimentally via the force-deflection relationship for the beam. This calibration was achieved by loading the cantilever arrangement at the point of waveguide entry with known masses and measuring the beam deflection at this point with a dial gauge. All results $(\mathrm{n}=6)$ for forces up to 10 Newtons are presented in Figure $3 b$.

Each time the tissue is partially perforated this failure results in a drop in applied force on the beam. This is related back to a change in beam deflection, $\delta_{\text {fail }}$, using the forcedeflection relationship of the beam, as shown in Figure $3 b$. The wire waveguide indentation into tissue, $\delta_{\mathrm{i}}$, is given in equation 4 . A benefit of this arrangement is the detection and quantifying of tissue perforation depth, $\delta_{\text {fail }}$, at each stage.

$\delta_{\mathrm{i}}=\delta_{\text {tip }}-\delta_{\text {beam }}-\sum \delta_{\text {fail }}$

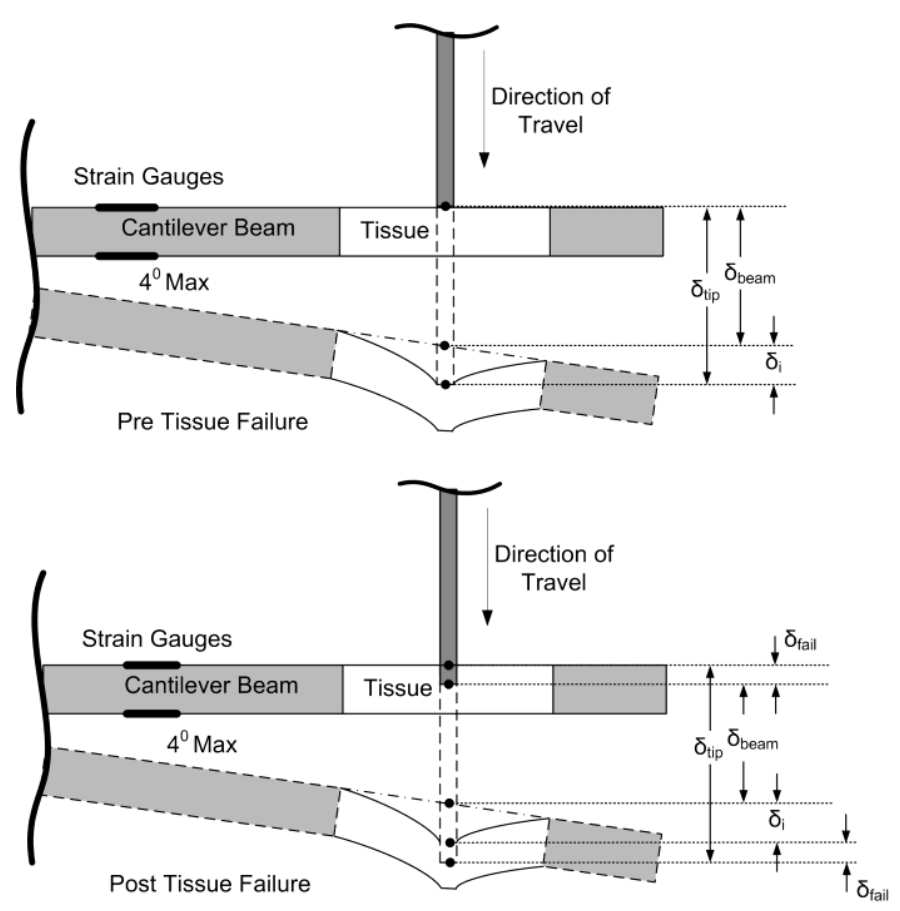

Fig. 3a. Close-up diagram of cantilever beam and tissue with displacement references. Note: the beam deflection in the diagram is exaggerated for visual purposes and does not exceed $4^{0}$ in practice. 


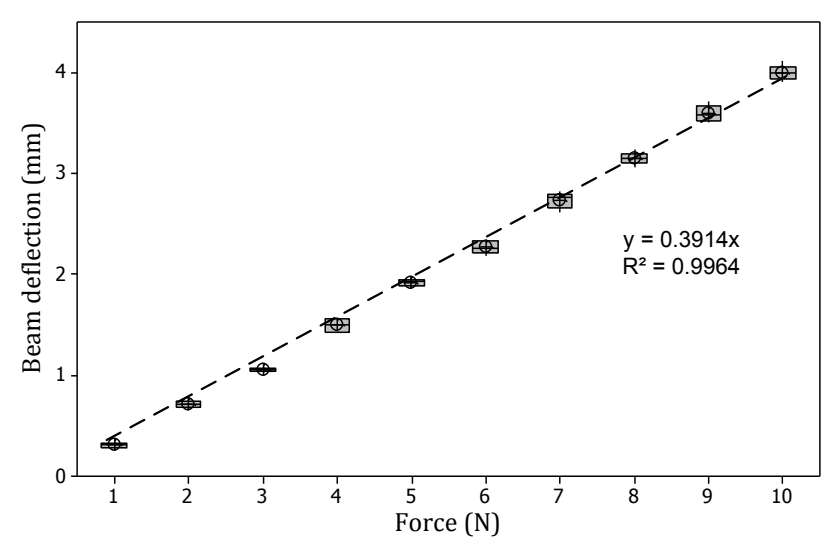

Fig. 3b. Calibration of the cantilever beam: Beam deflection versus applied force at wire waveguide point of entry $(n=6)$.

\section{Cavitation detection}

The tank was fitted with a miniature hydrophone (Model B/200, Neptune Sonar Limited, Kelk Lake, East Yorkshire, United Kingdom, unfocused, $9.0 \mathrm{~mm}$ diameter) with a flat response up to $180 \mathrm{kHz}$ and with a resonant frequency of 240 $\mathrm{kHz}$. The acoustic pressures generated by the vibrating wire waveguide distal tip in an open tank were measured using this hydrophone and a charge amplifier (Brüel \& Kjær, Charge amplifier Type 2635). The resulting amplified voltage signal was read into the data acquisition system to process and display the data; the sampling rate was $80 \mathrm{kHz}$ (Sound and Vibration Tool Kit, National Instruments). For cavitation detection a Fast Fourier Transform (FFT) of the acoustic time signal was conducted.

Based on reports by others [21, 22, 35], characteristic markers of stable cavitation include sub (e.g. f/2), super (e.g. 2f) and ultra (e.g. 3f/2) harmonic peaks of the fundamental frequency (measured at $22.5 \mathrm{kHz}$ ).

For inertial cavitation detection, a frequency band within the FFT signal, absent of significant harmonics, was extracted $(16.5-17 \mathrm{kHz})$. A real time analysis of the broadband noise in the frequency band was plotted for increasing acoustic intensities. An increase and a leveling of the broadband noise suggests operation in the inertial cavitation region $[24,36]$.

To further validate the onset of inertial cavitation, a b-mode ultrasonic imaging device (Philips ATL HDI 5000, L74 transducer, operating between 4-7 MHz) was used to visualize the cavitation at these power input settings (amplitudes of vibration).

\section{E. Tissue preparation and testing}

Porcine aortic vascular tissue was excised less than 24 hours after death and stored in a $0.9 \%$ saline solution and refrigerated before testing. The descending thoracic aorta was extracted and connective tissue was removed. Samples which included branched arteries were rejected. The tissue samples $(10 \times 20 \mathrm{~mm})$ were cut from radial sections and secured in the cantilever. Sample thickness was between $2.5-3.5 \mathrm{~mm}$. The cantilever arrangement was then lowered into the thermostatic tank which is filled with water and held at $37^{\circ} \mathrm{C} \pm 0.1$.
With the tissue samples secured in the cantilever and submerged in the thermostatic tank, the ultrasonic wire waveguide was advanced towards the tissue samples at a constant feed rate of $38 \pm 2 \mathrm{~mm} / \mathrm{min}$ for a range of power settings. The ultrasound was transmitted in continuous mode.

Tests were conducted using six tissue samples for each power setting; wire tissue perforation with no ultrasound energy and at four ultrasonic power settings was tested (30 tests in total). The wire waveguide was advanced through the tissue sample until complete perforation occurred. The real time force profile and visual observation was used as an indicator that the tissue had been fully perforated. Total time to perforate the tissue was 6.27 seconds (mean, $\sigma=2.02$ ).

\section{F. Histological studies}

Tissue samples were stored in a $10 \%$ buffered formalin solution after testing and processed to paraffin wax. $5 \mu \mathrm{m}$ samples were cut using a rotary microtome (Microm, HM 325). These samples were then dewaxed and stained using Haemotoxylin and Eason (H\&E) staining protocols. Samples were then viewed under light microscopy.

\section{RESULTS AND DISCUSSION}

\section{A. High frequency wire waveguide apparatus characterization}

Through initial testing and some preliminary work [37], a suitable wire waveguide length for high frequency mechanical transmission, apparatus-test rig integration and tissue testing was found to be near an anti-resonant wire waveguide length of $132 \mathrm{~mm}$. For six wires at this length, the wire waveguide distal tip amplitude of vibration versus ultrasonic generator input power setting (Setting 1-5, arbitrary units (au)) was measured using an optical microscope and imaging software. The results are shown in Table 1. The amplitudes of vibration values ranged from 17.8-34.3 $\mu \mathrm{m}$ (mean).

Using the relationships outlined above, the distal tip acoustic intensities were calculated for the mean amplitude of vibration values. The acoustic intensities ranged from 1.03 - 3.83 $\mathrm{W} / \mathrm{cm}^{2}$ (water at $37^{0} \mathrm{C}$ ). This information is presented in Table 1 also. Transmission at power setting 1 (au) was intermittent and as a result tissue tests were not conducted at this power setting.

TABLE I

WiRe WAVEGUIDE OPERATING PARAMETERS

\begin{tabular}{ccc}
\hline \hline & Frequency of operation & $\mathbf{2 2 . 5} \mathbf{k H z}$ \\
\hline \hline Power setting & $\begin{array}{c}\text { Amplitude of vibration (mean) } \\
(\mu \mathrm{m})\end{array}$ & $\begin{array}{c}\text { Acoustic } \\
\text { intensity }\left(\mathrm{W} / \mathrm{cm}^{2}\right)\end{array}$ \\
\hline $1^{*}$ & $17.8^{*}$ & $1.03^{*}$ \\
2 & 22.5 & 1.65 \\
3 & 27.8 & 2.51 \\
4 & 31.4 & 3.21 \\
5 & 34.3 & 3.83
\end{tabular}

Performance characteristics of wire waveguide apparatus operating at 22.5 $\mathrm{kHz}$ with $1.0 \mathrm{~mm}$ diameter distal tip. Acoustic fluid properties: density $=991$ $\mathrm{kg} / \mathrm{m}^{3}$, speed of sound $=1520 \mathrm{~m} / \mathrm{s}$, values taken for water at $37^{\circ} \mathrm{C}$.

* Intermittent transmission- not suitable for tissue testing. 


\section{B. Cavitation detection}

Figure 4(a) shows an example FFT plot of the acoustic spectrum produced by an energized $1.0 \mathrm{~mm}$ wire waveguide (acoustic intensity $1.65 \mathrm{~W} / \mathrm{cm}^{2}$ ). A spectral peak at the operating frequency of $22.5 \mathrm{kHz}$ was observed in the FFTs of the acoustic spectra for all acoustic intensities. Stable cavitation was observed as harmonic peaks (sub and ultra) when the wire waveguide was energized, as shown in Figure 4(a).

Figure 4(b) shows an example FFT plot of the acoustic spectrum produced by an energized $1.0 \mathrm{~mm}$ wire waveguide (acoustic intensity $3.21 \mathrm{~W} / \mathrm{cm}^{2}$ ). A frequency band absent of any distinct harmonics $(16.5-17 \mathrm{kHz})$ was extracted and analyzed for inertial cavitation, as shown in Figure 4(b). The wire waveguide acoustic intensity was increased and the broadband noise in this frequency band was recorded, see Figure 4(c). An initial increase in broadband noise was first recorded as the wire waveguide was energized. This noise level plateaued for values of acoustic intensity level greater than $3.21 \mathrm{~W} / \mathrm{cm}^{2}$ despite the fact that the wire waveguide distal tip acoustic intensities were increasing. As discussed above and reported by others [24] this is an indicator of operation in the inertial cavitation region.

In further tests using higher acoustic intensities (up to 5.41 $\mathrm{W} / \mathrm{cm}^{2}$, but not used in the tissue tests) and for a number of other frequency bands, similar results were obtained.

Cavitation activity was also observed visually using the bmode scanner at these intensities. It was found that, for the 1.0 $\mathrm{mm}$ diameter waveguide, the cavitation threshold occurred above $31.4 \mu \mathrm{m}$ amplitude of vibration, corresponding to an approximate distal tip acoustic intensity of $3.21 \mathrm{~W} / \mathrm{cm}^{2}$. This value is similar to those values reported in the literature and mentioned previously.

\section{Tissue perforation}

Figure 5 shows examples of the tissue perforation force versus distal tip indentation into the tissue, $\delta_{\mathrm{i}}$, for two distal tip acoustic intensities $\left(2.51\right.$ and $\left.3.83 \mathrm{~W} / \mathrm{cm}^{2}\right)$ and also at 0 $\mathrm{W} / \mathrm{cm}^{2}$ (i.e. non-energized wire waveguide). Using the force perforation profile for $2.51 \mathrm{~W} / \mathrm{cm}^{2}$, as an example, the force profiles can be described as having a number of features:

1) An initial rise in force up to a threshold value whereby the tissue fails and perforation of the tissue begins, the perforation initiation force, $\mathrm{F}_{\mathrm{i}}$, point ' 1 ' on the graph. The area under the curve up to this initial failure point represents the work done to initiate perforation, the perforation initiation energy, $\mathrm{E}_{\mathrm{i}}$, using the method similar to McCarthy et al [28]. In the case of the non-energized wire all samples failed in a single stage. The total energy for perforation was also calculated from the force profile data by calculating the area under the entire curve, up to the complete tissue perforation point indicated by the ' $x$ '.

2) With activation of the wire waveguide, and in particular at higher acoustic intensities, a multi-stage failure was evident. It was found that with intensities of $1.65 \mathrm{~W} / \mathrm{cm}^{2}$ and greater, failure of the tissue occurs in multiple stages
(2-3 stages identified, see points ' 1,2 and $x$ '). It should be noted that the magnitude of the perforation initiation force was not always the greatest force encountered during the perforation; in some cases the second or third peak was greater, as in the $2.51 \mathrm{~W} / \mathrm{cm}^{2}$ example where the second perforation force ' 2 ' was greater than ' 1 '.
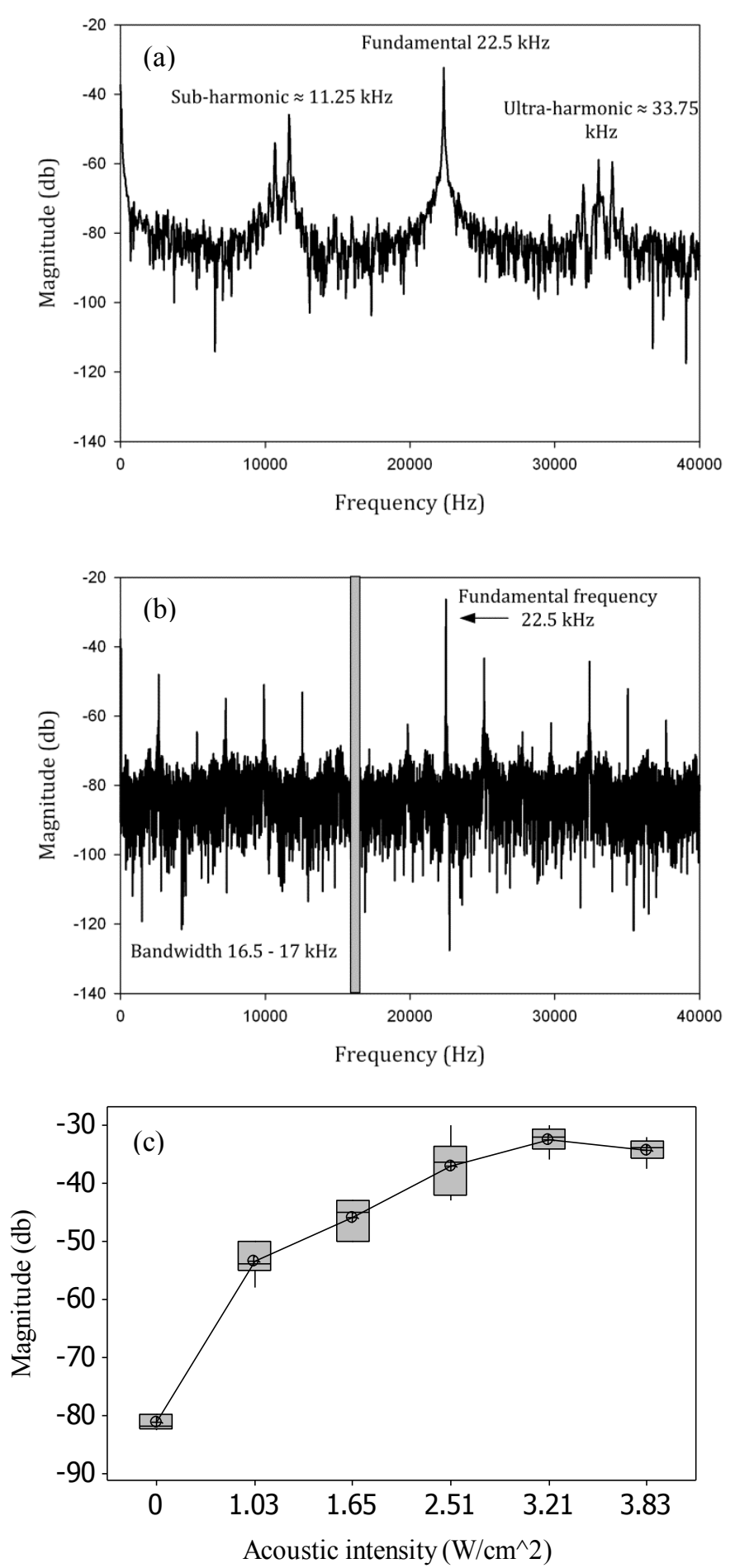

Fig. 4. (a) Acoustic spectrum of waveguide operating at $1.65 \mathrm{~W} / \mathrm{cm}^{2}$ (b) Acoustic spectrum of waveguide operating at $3.21 \mathrm{~W} / \mathrm{cm}^{2}$ (c) Acoustic broadband noise versus acoustic intensity for bandwidth of $16.5-17 \mathrm{kHz}$ in FFT spectrum. 


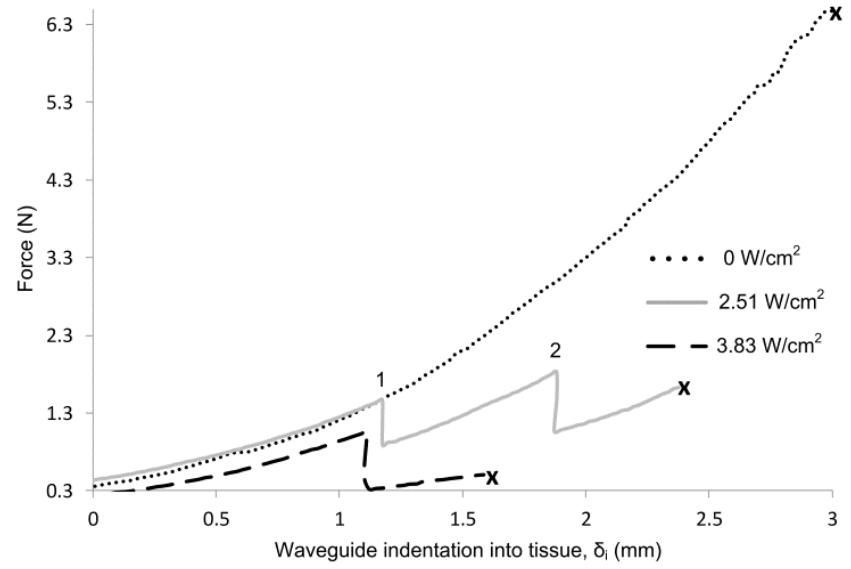

Fig. 5. Force versus distal tip indentation into tissue, $\delta$ i, profiles for individual tests, for a range of acoustic intensities. Note: Non-energized is depicted as 0 $\mathrm{W} / \mathrm{cm}^{2}$.

No more than three force peaks were detected for any test. The results generally show a reduction in the perforation forces with increasing acoustic intensities.

Figure 6 shows the results for the perforation initiation force for all tests ( 6 tests per acoustic intensity, 30 in total). With the non-energized wire waveguide the perforation initiation force is $6.13 \mathrm{~N}$ (mean, $\sigma=0.60$ ). At the lowest acoustic intensity of $1.65 \mathrm{~W} / \mathrm{cm}^{2}$ the perforation initiation force is reduced to 2.46 $\mathrm{N}$ (mean, $\sigma=0.49$ ). The perforation initiation force is further reduced to $1.26 \mathrm{~N}$ (mean, $\sigma=0.14$ ) with an energized wire waveguide with the highest acoustic intensity of $3.83 \mathrm{~W} / \mathrm{cm}^{2}$, an $80 \%$ reduction in force compared with the non-energized waveguide.

A one way ANOVA was performed on the perforation initiation force data. A Tukey's test showed to a $95 \%$ confidence level that the perforation initiation forces for the acoustic intensities above $2.51 \mathrm{~W} / \mathrm{cm}^{2}$ were not significantly different. There was no significant reduction in the perforation initiation force when the wire waveguide was operated above the cavitation threshold intensity of $3.21 \mathrm{~W} / \mathrm{cm}^{2}$. Standard deviation was lowest (both $\sigma=0.135$ ) for the higher acoustic intensities tested $\left(3.21 \mathrm{~W} / \mathrm{cm}^{2}\right.$ and $\left.3.83 \mathrm{~W} / \mathrm{cm}^{2}\right)$. In comparison for a non-energized wire waveguide the standard deviation was much greater $(\sigma=0.60)$.

The resulting perforation initiation energy, $\mathrm{E}_{\mathrm{i}}$, was calculated and plotted in Figure 7. The energy for perforation initiation for a non-energized wire was $7.75 \mathrm{~mJ}$ (mean, $\sigma=$ 1.41). This reduced to $2.38 \mathrm{~mJ}$ (mean, $\sigma=0.71$ ) at the lowest acoustic intensity of $1.65 \mathrm{~W} / \mathrm{cm}^{2}$. The minimum perforation initiation energy was measured as $1.02 \mathrm{~mJ}$ (mean, $\sigma=0.46$ ) at the highest acoustic intensity setting of $3.83 \mathrm{~W} / \mathrm{cm}^{2}$. The lowest standard deviation $(\sigma=0.22)$ was measured at acoustic intensity $2.51 \mathrm{~W} / \mathrm{cm}^{2}$, this increased for the higher acoustic intensities $\left(3.21 \mathrm{~W} / \mathrm{cm}^{2}, \sigma=0.33\right.$ and $\left.3.83 \mathrm{~W} / \mathrm{cm}^{2}, \sigma=0.46\right)$.

The total perforation energy $\left(\mathrm{E}_{\mathrm{t}}\right)$ versus acoustic intensity is plotted in Figure 8. For a non-energized wire waveguide the total perforation energy was $7.75 \mathrm{~mJ}$ (mean, $\sigma=1.41$, note: same as perforation initiation energy as failure occurred in one stage for all tests). This was reduced to $3.07 \mathrm{~mJ}$ (mean, $\sigma=$
$1.49)$ at an acoustic intensity setting of $1.65 \mathrm{~W} / \mathrm{cm}^{2}$.

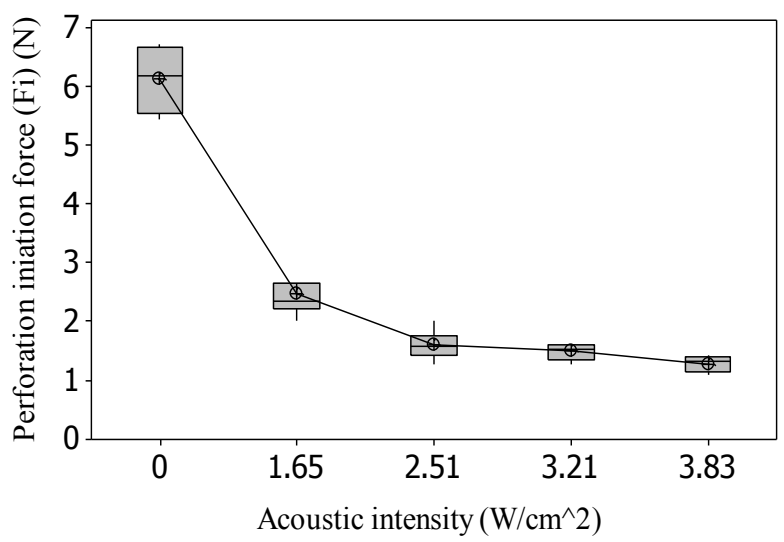

Fig. 6. Perforation initiation force $\left(\mathrm{F}_{\mathrm{i}}\right)$ for a range of acoustic intensities.

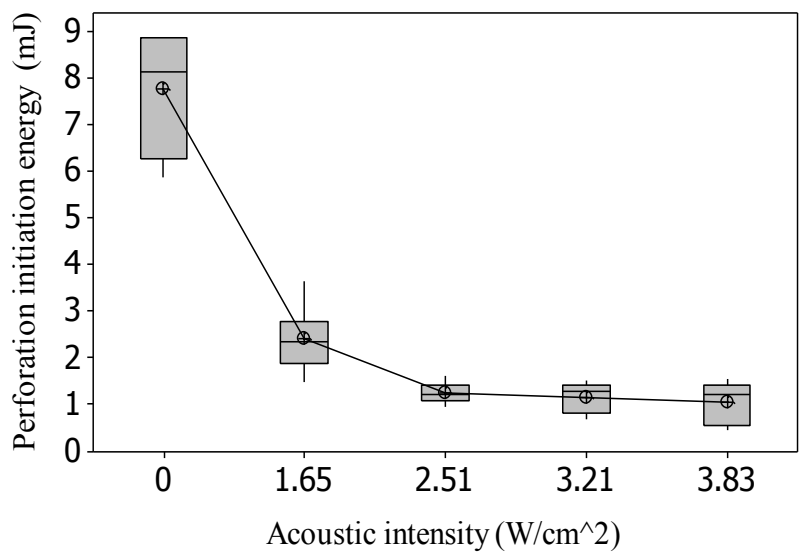

Fig. 7. Perforation initiation energy $\left(E_{i}\right)$ for a range of acoustic intensities.

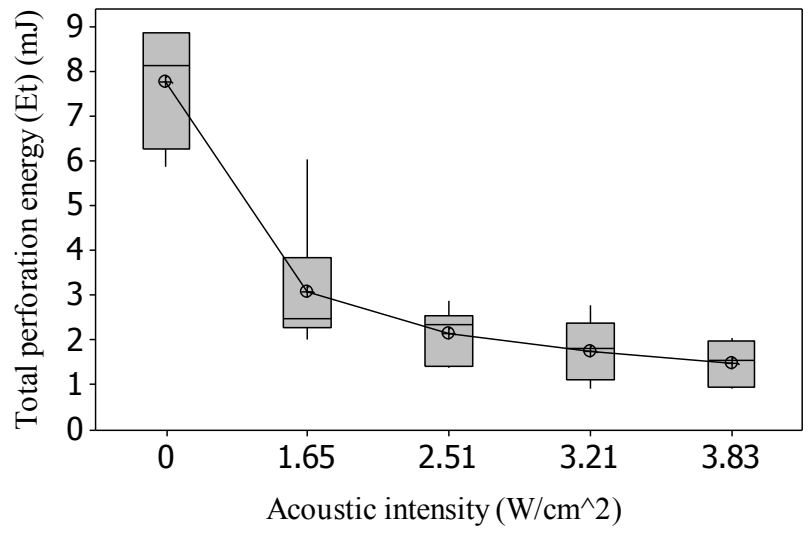

Fig. 8. Total perforation energy $\left(E_{t}\right)$ for a range of acoustic intensities.

The energy required to completely perforate the tissue at the highest acoustic intensity $3.83 \mathrm{~W} / \mathrm{cm}^{2}$ was reduced to 1.45 (mean, $\sigma=0.52$ ). The perforation initiation force, energy and total perforation energy are also presented in Table 2. 
TABLE 2

TISSUE PERFORATION FORCE AND ENERGY

\begin{tabular}{|c|c|c|c|}
\hline $\begin{array}{l}\text { Acoustic } \\
\text { intensity } \\
\left(\mathrm{W} / \mathrm{cm}^{2}\right)\end{array}$ & $\begin{array}{l}\text { Perforation } \\
\text { initiation force, } F_{i} \\
(\mathrm{~N})\end{array}$ & $\begin{array}{l}\text { Perforation } \\
\text { initiation } \\
\text { energy, } E_{\mathrm{i}}(\mathrm{mJ})\end{array}$ & $\begin{array}{l}\text { Total } \\
\text { perforation } \\
\text { energy, } E_{t}(\mathrm{~mJ})\end{array}$ \\
\hline 0 & $\begin{array}{c}6.13 \\
(\text { mean, } \sigma=0.60)\end{array}$ & $\begin{array}{c}7.75 \\
(\text { mean, } \sigma= \\
1.41)\end{array}$ & $\begin{array}{c}7.75 \\
(\text { mean, } \sigma= \\
1.41)\end{array}$ \\
\hline 1.65 & $\begin{array}{c}2.46 \\
(\text { mean, } \sigma=0.49)\end{array}$ & $\begin{array}{c}2.38 \\
(\text { mean, } \sigma= \\
0.71)\end{array}$ & $\begin{array}{c}3.07 \\
(\text { mean, } \sigma= \\
1.49)\end{array}$ \\
\hline 2.51 & $\begin{array}{c}1.59 \\
(\text { mean, } \sigma=0.25)\end{array}$ & $\begin{array}{c}1.23 \\
(\text { mean, } \sigma= \\
0.22)\end{array}$ & $\begin{array}{c}2.13 \\
(\text { mean, } \sigma= \\
0.60)\end{array}$ \\
\hline 3.21 & $\begin{array}{c}1.48 \\
(\text { mean, } \sigma=0.13)\end{array}$ & $\begin{array}{c}1.14 \\
(\text { mean, } \sigma= \\
0.33)\end{array}$ & $\begin{array}{c}1.75 \\
(\text { mean, } \sigma= \\
0.71)\end{array}$ \\
\hline 3.83 & $\begin{array}{c}1.26 \\
(\text { mean, } \sigma=0.14)\end{array}$ & $\begin{array}{c}1.02 \\
(\text { mean, } \sigma= \\
0.46)\end{array}$ & $\begin{array}{c}1.45 \\
(\text { mean, } \sigma= \\
0.52)\end{array}$ \\
\hline
\end{tabular}

Perforation initiation force $\left(\mathrm{F}_{\mathrm{i}}\right)$, perforation initiation energy $\left(\mathrm{E}_{\mathrm{i}}\right)$ and total perforation energy $\left(E_{t}\right)$ for all acoustic intensities using a $1.0 \mathrm{~mm}$ wire waveguide at $22.5 \mathrm{kHz}$.

\section{Histological Examination}

Section cuts (B-B) of the tissue samples which were perforated with a non-energized wire waveguide and with a wire waveguide operating at $2.51 \mathrm{~W} / \mathrm{cm}^{2}$ are shown in Figure 9 (a) and (b), respectively. The hole geometry at point of entry, plan view (A-A), are shown in Figure 9 (ai) and (bi) inset. For the non-energized waveguide an irregular shaped entry hole is generally observed as shown in Figure 9 (ai).

The histology images confirm that for a non-energized waveguide the perforation hole recloses following removal of the waveguide as shown in Figure 9 (a). This suggests that tissue is merely separated by the wire perforation with minimal tissue removal. When high frequency vibrations are applied to the wire waveguide a well defined entry hole is created in the tissue as shown in Figure 9 (bi). Multistage tissue perforation is evident in Figure 9 (b).

Histological examination of the tissue revealed a relatively thin adventitia layer in the porcine aorta when compared with the media layer. As a result, it was evident that there were multiple distinct failures within the media layer alone, ruling out the possibility that failure occurred at the boundaries between arterial layers. For the image shown in Figure 9 (b) the acoustic intensity was $2.51 \mathrm{~W} / \mathrm{cm}^{2}$ and a three stage perforation is observed corresponding to the force profile data from the tissue test where three force peaks were measured, as shown in Figure 5.

The histology images where vibrations are applied to the wire waveguide present strong evidence of tissue removal; the perforated hole remains after waveguide removal. At the tissue failure locations it can also be seen that the tissue has become striated and compressed or fused, with evidence of delamination in the vicinity.

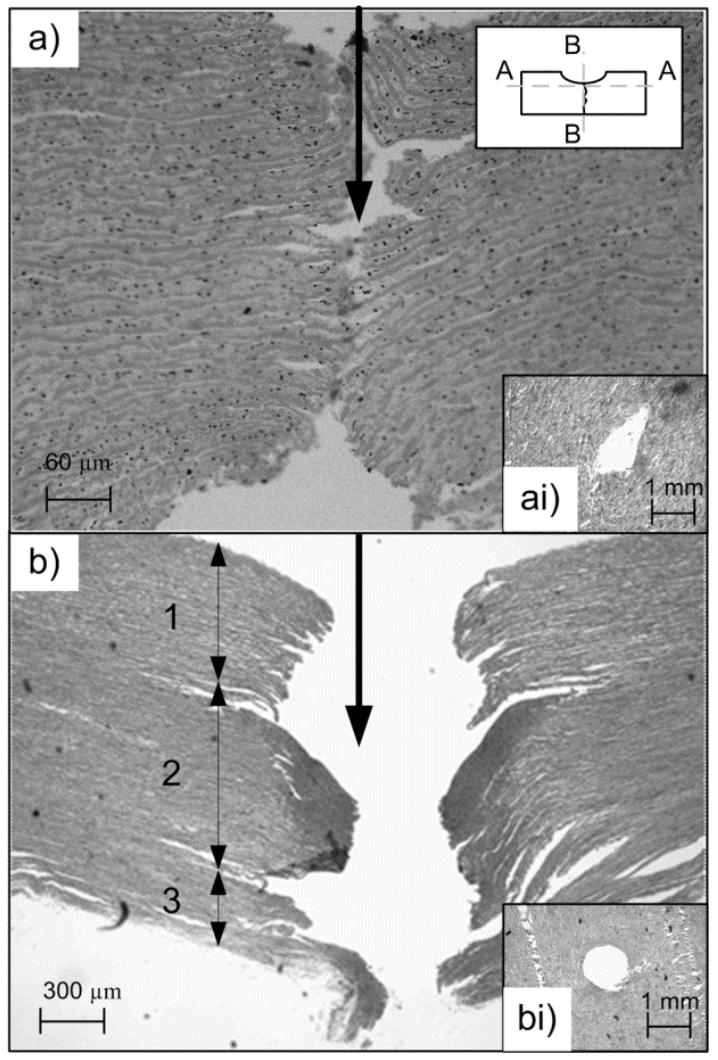

Fig. 9. a) Image of artery post perforation with a non-energized wire waveguide. $H \& E$ stain and magnification $=20 x$. b) Image of artery post perforation with an energized wire waveguide (intensity $=2.51 \mathrm{~W} / \mathrm{cm}^{2}$ ). $\mathrm{H} \& \mathrm{E}$ stain and magnification $=4 \mathrm{x}$. Large arrow indicates travel of waveguide.

\section{CONCLUSIONS}

The use of high frequency mechanical/ ultrasonic vibrations delivered to various surgical tool end effectors has become common place in a number of tissue removal applications. Most work to date has focused on high intensity applications in excess of $400 \mathrm{~W} / \mathrm{cm}^{2}$. This work focused on how low acoustic intensities, less than $4 \mathrm{~W} / \mathrm{cm}^{2}$ affect soft tissue under perforation.

The results show that soft tissue has an increased susceptibility to perforation under the action of the energized wire waveguides when compared with non energized wires. The results show significant reductions in forces required to perforate the tissue. Cavitation may play a reduced role in decreasing the perforation initiation force at these lower acoustic intensities, with direct mechanical contact between waveguide and tissue being the primary tissue disruption mechanism.

The results also show that, where desirable, soft tissue can be perforated at lower forces or ablated under the action of high frequency mechanical vibrations in wire waveguides. But in applications close to critical anatomical structures, such as the arterial wall in cardiovascular diseased tissue removal, there may be an increased risk of unwanted perforation or damage of adjacent tissues. When high frequency vibrations are applied to waveguides, the range of forces and energy to perforate the tissue are more predictable. This may allow for 
greater control of tissue removal.

These studies were conducted at a perforation angle of $90^{\circ}$, whereby the wire waveguide was engaged perpendicular to the tissue; angled entry may be more applicable. The results may aid device design and power selection during precision tissue removal applications.

\section{ACKNOWLEDGMENT}

The authors would like to thank Dr. Jacinta Browne and Dr. Helen Lambkin, DIT, for their assistance.

\section{REFERENCES}

[1] R. J. Siegel, and H. Luo, "Ultrasound thrombolysis," Ultrasonics, vol. 48 , no. 4, pp. 312-320, 2008.

[2] T. H. Gail, "Therapeutic applications of ultrasound," Progress in Biophysics and Molecular Biology, vol. 93, no. 1-3, pp. 111-129.

[3] J. Wu, and W. Nyborg, Emerging Therapeutic Ultrasound, Singapore: World Scientific Publishing Co Pte Ltd, 2006.

[4] R. J. Siegel, J. Gunn, A. Ahsan et al., "Use of therapeutic ultrasound in percutaneous coronary angioplasty. Experimental in vitro studies and initial clinical experience," Circulation, vol. 89, no. 4, pp. 1587-1592, April 1, 1994.

[5] U. Rosenschein, L. A. Rozenszajn, L. Kraus et al., "Ultrasonic angioplasty in totally occluded peripheral arteries. Initial clinical, histological, and angiographic results," Circulation, vol. 83, no. 6, pp. 1976-1986, June 1, 1991.

[6] L. L. Demer, M. Ariani, and R. J. Siegel, "High Intensity Ultrasound Increases Distensibility of Calcific Atherosclerotic Arteries," Journal of the American College of Cardiology, vol. 18, pp. 1259-62, 1991.

[7] I. R. Makin, and E. C. Everbach, "Measurement of Pressure and Assessment of Cavitation for a $22.5 \mathrm{kHz}$ Intra-arterial Angioplasty Device," Acoustic Society of America, 1996.

[8] S. Atar, H. Luo, T. Nagai et al., "Ultrasonic Thrombolysis: Catheter-Delivered and Transcutaneous Applications," European Journal of Ultrasound, vol. 9, no. 1, pp. 39-54, 1999.

[9] G. B. McGuinness, M. P. Wylie, and G. P. Gavin, "Ablation of Chronic Total Occlusions Using Kilohertz-Frequency Mechanical Vibrations in Minimally Invasive Angioplasty Procedures," Critical Reviews in Biomedical Engineering, vol. 38, no. 6, 2010.

[10] U. Rosenschein, A. Frimerman, S. Laniado et al., "Study of the Mechanism of Ultrasound Angioplasty from Human Thrombi and Bovine Aorta.," American Journal of Cardiology, vol. 74, pp. 1263-6, 1994

[11] "Press Release: FlowCardia Inc. Receives European Regulatory Approval and Successfully Completes U.S. Feasibility Clinical Trial," FlowCardia Inc., 2005.

[12] "Press Release: FlowCardia, Inc. Announces 510(k) Clearance for the CROSSER ${ }^{\mathrm{TM}} 14$ Chronic Total Occlusion Recanalization System - A New, Minimally Invasive Option to Bypass Surgery ", FlowCardia, Inc., 2007.

[13] N. G. William, W. Chen, P. Lee et al., "Initial Experience and Safety in the Treatment of Chronic Total Coronary Occlusions with a New Optical Coherent Reflectometry-Guided Radiofrequency Ablation Guidwire," The American Journal of Cardiology, vol. 92, no. 6, pp. 732-734, 2003.

[14] B. Meier, Current Best Practice in Interventional Cardiology, pp. 43-44: John Wiley and Sons, 2009.

[15] J. A. Grantham, S. P. Marso, J. Spertus et al., "Chronic total occlusion angioplasty in the United States," JACC Cardiovasc Interv, 6, pp. 479-86, United States, 2009.

[16] P. G. Yock, and P. J. Fitzgerald, "Catheter-Based Ultrasound Thrombolysis, Shake,Rattle and Reperfuse," Circulation, vol. 95, pp. 1360-1362, 1997.

[17] G. Drobinski, D. Brisset, F. Philippe et al., "Effects of Ultrasound Energy on Total Peripheral Artery Occlusions: Initial Angiographic and Angioscopic Results," Journal of Interventional Cardiology, vol. 6, no. 2, pp. 157-163, 1993.
[18] T. A. Fischell, M. A. Abbas, G. W. Grant et al., "Ultrasonic Energy. Effects on Vascular Function and Integrity," Circulation, vol. 84, no. 4, pp. 1783-1795, October 1, 1991.

[19] H. Hasanzadeh, M. Mokhtari-Dizaji, S. Z. Bathaie et al., "Evaluation of correlation between chemical dosimetry and subharmonic spectrum analysis to examine the acoustic cavitation," Ultrasonics Sonochemistry, vol. 17, no. 5, pp. 863869.

[20] Z. Xu, "Controlled ultrasound tissue erosion: The role of dynamic interaction between insonation and microbubble activity," $J$. Acoust. Soc. Am., vol. 117, no. 1, pp. 424, 2005.

[21] ANSI, "Bubble Detection and Cavitation Monitoring," Acoustic Society of America, 2002.

[22] S. Datta, C.-C. Coussios, A. Y. Ammi et al., "UltrasoundEnhanced Thrombolysis Using Definity ${ }^{\circledR}$ as a Cavitation Nucleation Agent," Ultrasound in Medicine \& Biology, vol. 34, no. 9, pp. 1421-1433, 2008.

[23] D. M. Hallow, A. D. Mahajan, T. E. McCutchen et al., "Measurement and correlation of acoustic cavitation with cellular bioeffects," Ultrasound in Medicine \& Biology, vol. 32, no. 7, pp. $1111-1122,2006$

[24] J. Frohly, S. Labouret, C. Bruneel et al., "Ultrasonic cavitation monitoring by acoustic noise power measurement," The Journal of the Acoustical Society of America, vol. 108, no. 5, pp. 2012-2020, 2000.

[25] S. Datta, C.-C. Coussios, A. Y. Ammi et al., "UltrasoundEnhanced Thrombolysis Using Definity ${ }^{\circledR}$ as a Cavitation Nucleation Agent," Ultrasound in Medicine \&amp; Biology, vol. 34, no. 9, pp. 1421-1433, 2008.

[26] G. Weisz, and J. W. Moses, "New percutaneous approaches for chronic total occlusion of coronary arteries," Expert Review of Cardiovascular Therapy, vol. 5, pp. 231-241, 2007.

[27] T. D. Mast, S. M. Inder Raj, F. Waseem et al., "Bulk ablation of soft tissue with intense ultrasound: Modeling and experiments," The Journal of the Acoustical Society of America, vol. 118, no. 4, pp. 2715-2724, 2005

[28] W. W. Cimino, and L. G. Bond, "Physics of Ultrasonic Surgery Using Tissue Fragmentation: Part 1," Ultrasound Med Biol, vol. 22, pp. 89-100, 1996

[29] C. T. McCarthy, M. Hussey, and M. D. Gilchrist, "On the sharpness of straight edge blades in cutting soft solids: Part I indentation experiments," Engineering Fracture Mechanics, vol. 74, no. 14, pp. 2205-2224, 2007.

[30] T. Azar, and V. Hayward, "Estimation of the Fracture Toughness of Soft Tissue from Needle Insertion," in Proceedings of the 4th international symposium on Biomedical Simulation, London, UK, 2008, pp. 166-175.

[31] H. Al-Ameri, G. S. Mayeda, and D. M. Shavelle, "Use of highfrequency vibrational energy in the treatment of peripheral chronic total occlusions.," Catheterization and Cardiovascular Interventions, vol. 74, no. 7, pp. 1110-1115, 2009.

[32] G. P. Gavin, G. B. McGuinness, F. Dolan et al., "Performance characteristics of a therapeutic ultrasound wire waveguide apparatus," International Journal of Mechanical Sciences, vol. 49, no. 3, pp. 298-305, 2007.

[33] P. M. Morse, Vibration and Sound, pp. 311-326, New York: Acoustical Society of America, 1981.

[34] W. L. Nyborg, "Basic Physics of Low Frequency Therapuetic Ultrasound. Ultrasound Angioplasty," Developments in Cardiovascular Medicine: Kluwer Academic Publishers, 1996.

[35] T. G. Leighton, The Acoustic Bubble: Academic Press, 1994.

[36] M. Hodnett, R. Chow, and B. Zeqiri, "High-frequency acoustic emissions generated by a $20 \mathrm{kHz}$ sonochemical horn processor detected using a novel broadband acoustic sensor: a preliminary study," Ultrasonics Sonochemistry, vol. 11, no. 6, pp. 441-454, 2004.

[37] M. P. Wylie, G. B. McGuinness, and G. P. Gavin, "Therapeutic ultrasound angioplasty: the risk of arterial perforation. An in vitro study.," Conf Proc IEEE Eng Med Biol Soc, vol. 2009, pp. 282-5, 2009. 